\title{
- Tumor ovariano das células da granulosa em vaca Simental - relato de caso
}

\section{- Ovarian granulosa cell tumor in a Simenthal cow - a case report}

* Nereu Carlos Prestes ${ }^{1}$ - CRMV-SP-n ${ }^{0} 2839$

Marco Antônio Alvarenga' ${ }^{1}$ - CRMV-SP-10\%169

EnioPedoneBandarra ${ }^{2}$-CRMV-SP-n ${ }^{0} 0786$

Sara Mariade Carvalhoe Suzano ${ }^{3}$-CRMV-SP- $n^{0} 12866$

MariângelaLozanoCruz $z^{4}$ CRMV-SP-n ${ }^{0} 8211$

\footnotetext{
${ }^{1}$ Docentes do Departamento de Reprodução Animal e Radiologia Veterinária - FMVZ - UNESP/Botucatu.

${ }^{2}$ Docente do Departamento de Clínica Veterinária - FMVZ - UNESP/Botucatu.

${ }^{3}$ Residente do Departamento de Clínica Veterinária - FMVZ - UNESP/Botucatu.

${ }^{4}$ Docente do Departamento de Cirurgia e Anestesiologia Veterinária - FMVZ - UNESP/Botucatu.
}

\section{RESUMO}

O objetivo do presente trabalho é relatar um caso de tumor das células da granulosa com sede no ovário esquerdo de uma vaca Simental de 3 anos de idade. A neoplasia mediu $10 \mathrm{~cm}$ no seu diâmetro maior e ao corte exibia formações císticas de diferentes diâmetros preenchidas por líquido. $\mathrm{O}$ exame histopatológico confirmou o diagnóstico presuntivo.

Palavras-chave: vaca, ovário, tumor das células da granulosa.

\section{Introdução e Revisão da Literatura}

A

$\mathrm{s}$ doenças que acometem os ovários dos animais domésticos são subdivididas em alterações que provocam aumento de volume, como os tumores, os cistos e os folículos anovulatórios e Naquelas que determinam redução de tamanho (hipoplasias), promovendo conseqüente distúrbio da forma e da função do órgão (McCUE, 1998).

Segundo McENTEE (1990), o tumor das células da granulosa é a neoplasia ovariana mais freqüente em vacas e éguas, sendo descrita com a mesma frequência em cadelas. Relatos semelhantes foram feitos por STICKLE et al. (1975) e NYACK e JOHNSON (1983).
* Faculdade de Medicina Veterinária e Zootecnia - UNESP Departamento de Reproduçāo Animal e Radiologia Veterinária Distrito de Rubiāo Júnior, s/n CEP 18.618-000-Botucatu -SP 
PRESTES, N. C.; ALVARENGA, M. A.; BANDARRA, E. P.; SUZANO, S. M. C.; CRUZ, M. L. Tumor ovariano das células da granulosa em vaca Simental - relato de caso / Ovarian granulosa cell tumor in a Simenthal cow - a case report. / Rev. educ. contin. CRMV-SP / Continuous Education Journal CRMV-SP, São Paulo, volume 4 , fascículo 1, p. $028-032,2001$

senvolvem simultaneamente. Existem relatos desta manifestação na cadela e na vaca, porém sem associação com sinais e sintomas de hiperglicemia, glicosúria, polidipsia e poliúria.

OBA et al. (1987), descreveram, em relato de caso, a ocorrência de tumores bilaterais das células da granulosa em ovários de uma vaca Nelore de 12 anos de idade, dos quais um apresentava formação cística enquanto o contra-lateral era sólido (compacto). O referido animal havia parido 3 vezes e a partir de então passou a apresentar cios irregulares e repeti-los após as inseminações. O ovário esquerdo media $40 \mathrm{~cm}$ de diâmetro.

Para WILSON et al. (1989), as éguas com tumor das células da granulosa podem manifestar estro prolongado, ciclos irregulares, ninfomania, anestro, ou comportamento masculinizado. Outras observações possíveis incluem sinais de cólica, laminite, desenvolvimento muscular anormal, caquexia e anemia. Concluíram que esse tipo de tumor é benigno. McENTEE (1990), também afirmou não ter observado metástases desta neoplasia em éguas e vacas. Contudo, STICKLE et al. (1975), afirmaram que em estudo de 13 cadáveres bovinos, foram encontrados metástases em 9 deles. Em seres humanos, o pro- blema das metástases é considerável, inclusive com taxa de sobrevivência de 50 a $60 \%$ após 5 anos do ato da remoção do tumor.

McENTEE (1990) afirmou que o primeiro relato de tumor das células da granulosa em ovário de bovinos foi realizado por GOLBERG (1920) e que BAUMMANN (1935), apresentara descrição detalhada e resultado histopatológico de 6 casos encontrados em matadouro. Descrevera que vacas afetadas tinham de 2 a 3 anos de idade, podendo manifestar ninfomania, virilismo ou ausência de sinais clínicos, na dependência do tipo de hormônio circulante produzido pelo ovário afetado. O tumor das células da granulosa em vacas apresenta superfície lisa ou lobulada que, ao corte, mostrase sólido ou há mistura de tecido compacto e formações císticas de diâmetro variável, os quais são preenchidas por líquido de coloração amarelada, alaranjada ou sanguinolenta. Focos de hemorragia ou necrose são evidentes nos tumores grandes.

Os métodos diagnósticos das neoplasias ovarianas incluem o histórico reprodutivo e o comportamento do animal associados à palpação retal. A confirmação deve ser realizada pelos exames complementares de dosagem hormonal, ou biópsia com exame histopa-

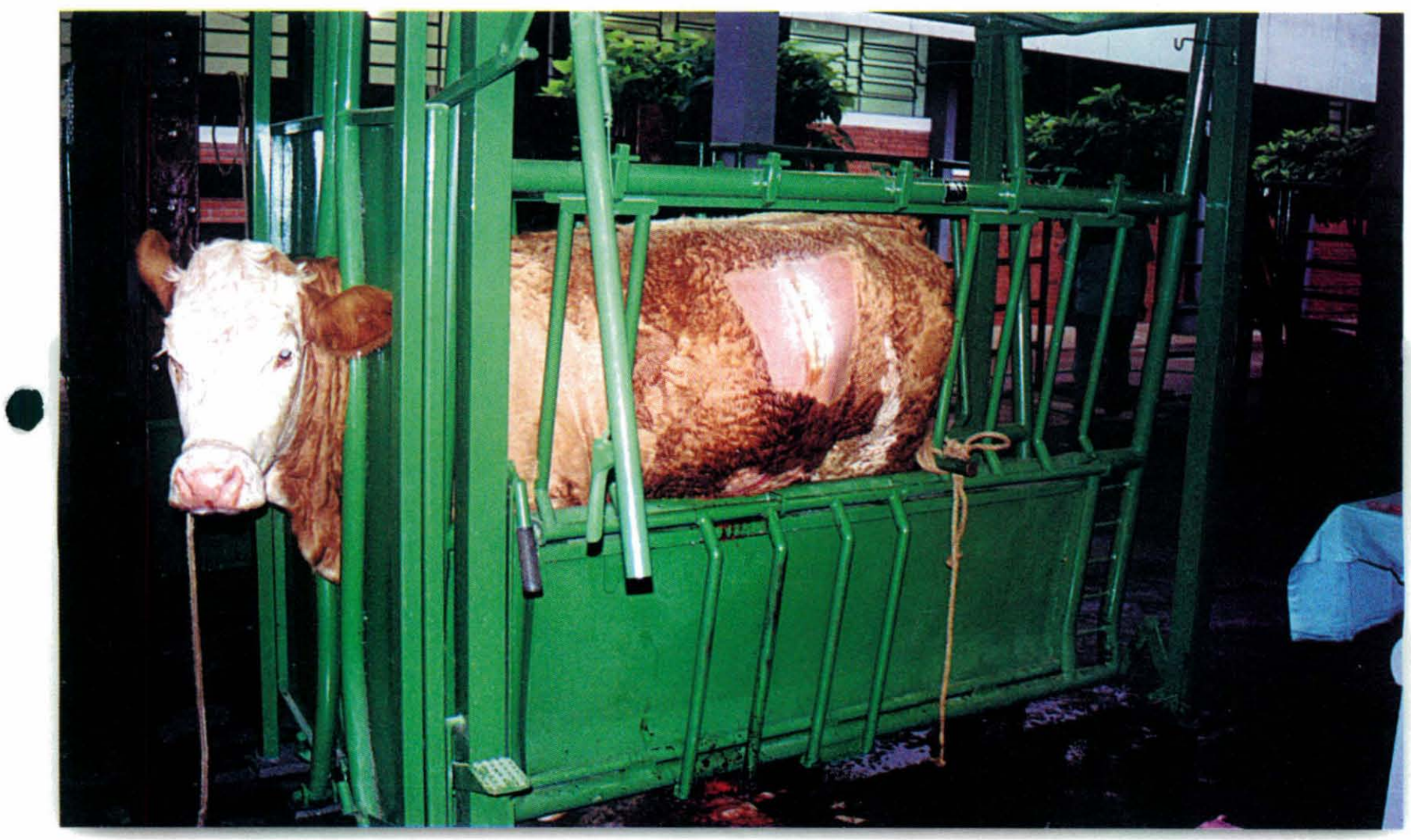

Figura 1. Vaca Simental contida no tronco, no pós-operatório imediato. 


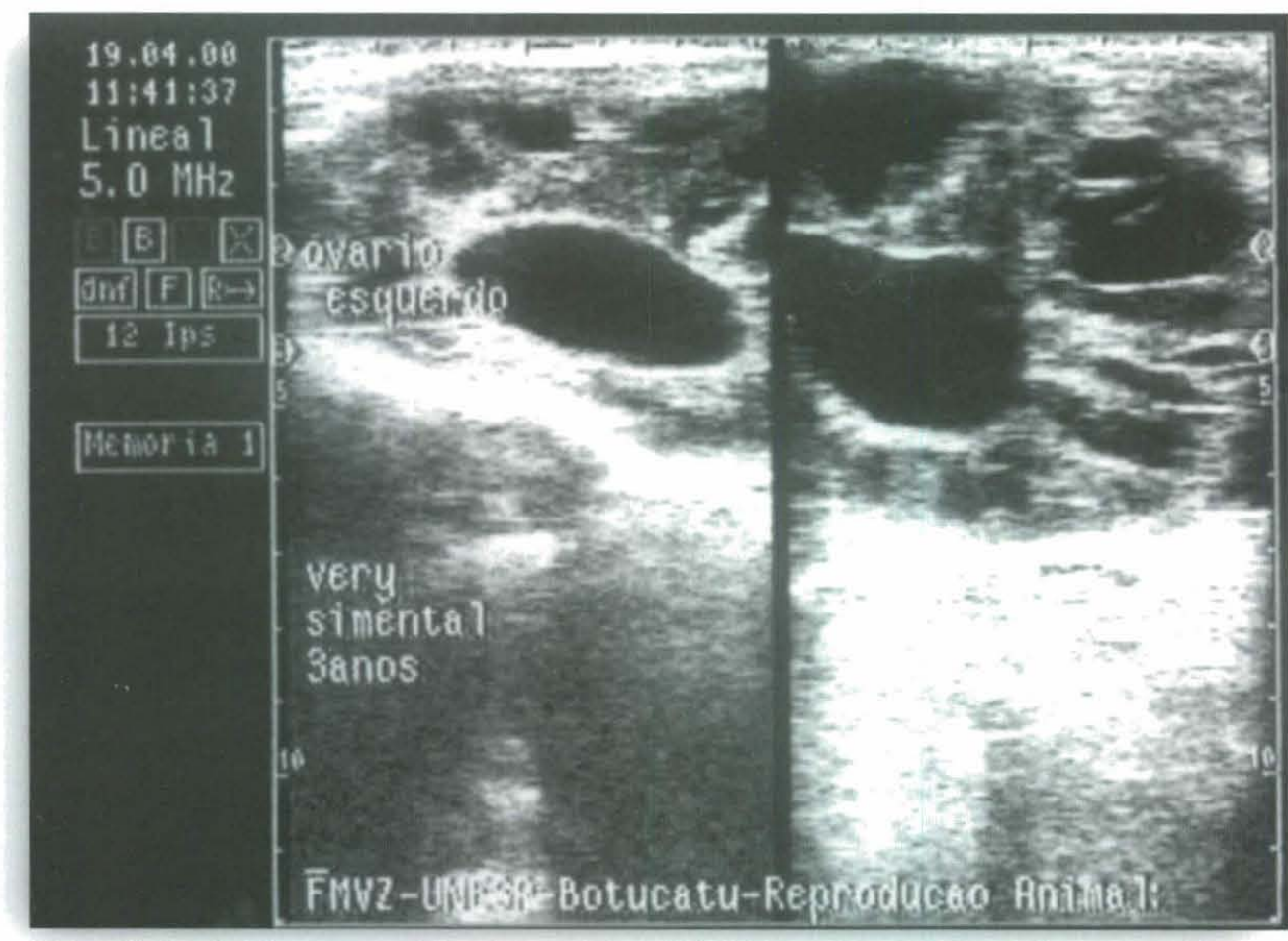

Figura 2. Detalhe do aspecto cístico do tumor das células da granulosa no exame ultra-sonográfico.

do ovário acometido. O ovário contra-lateral retoma a atividade cíclica normal em período de tempo variável (CORDES, 1969; STICKLE et al., 1975; WHITE e ALLEN, 1985; DORAN et al., 1988; HINRICH et al., 1989; WILSON et al., 1989; HINRICH et al., 1990; HINRICH et al., 1992; McCUE, 1998).

\section{Relato do caso}

Em abril do ano 2000, foi atendida pelo serviço de Reprodução Animal da Faculdade de Medicina Veterinária e Zootecnia - UNESP - Campus de Botucatu - SP, uma vaca Simental de 3 anos de idade, que havia apresentado episódio de abortamento há 5 meses. $\mathrm{O}$ animal

tológico, citologia aspirativa ou pela ultra-sonografia (WHITE e ALLEN, 1985; HINRICH et al., 1990; McCUE, 1998).

O tratamento preconizado é a ovariectomia. As vias de acesso possíveis nos grandes animais são a linha branca pré-retro-umbilical, fossa paralombar, via paramediana direita ou esquerda ou através do fundo vaginal. A escolha da via de acesso e do equipamento auxiliar irá depender da espécie e índole do animal, das condições técnicas, protocolo anestésico e do tamanho estava em atividade reprodutiva cíclica normal, porém todas as inseminações foram infrutíferas com retorno ao cio, não apresentando outras alterações físicas ou comportamentais (Figura 1).

À palpação retal, constatou-se um aumento de volume no ovário esquerdo com aproximadamente $10 \mathrm{~cm}$ de diâmetro. Na ultra-sonografia, a imagem revelou áreas císticas que variavam de 0,5 a $3 \mathrm{~cm}$ de diâmetro, contendo líquido de característica anecóica, intercaladas por septos ecogênicos, revelando-se

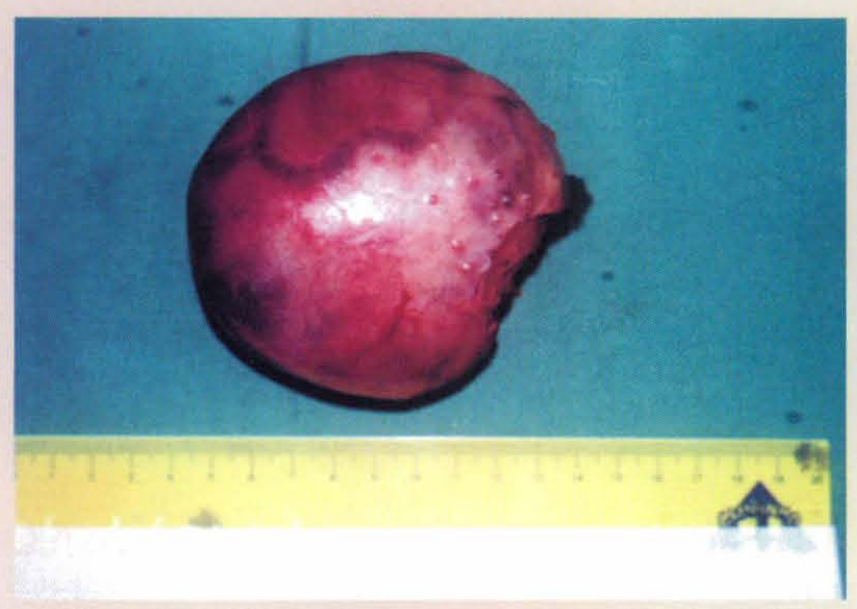

Figura 3. Ovário esquerdo acometido pela neoplasia imediatamente após a ovariectomia.

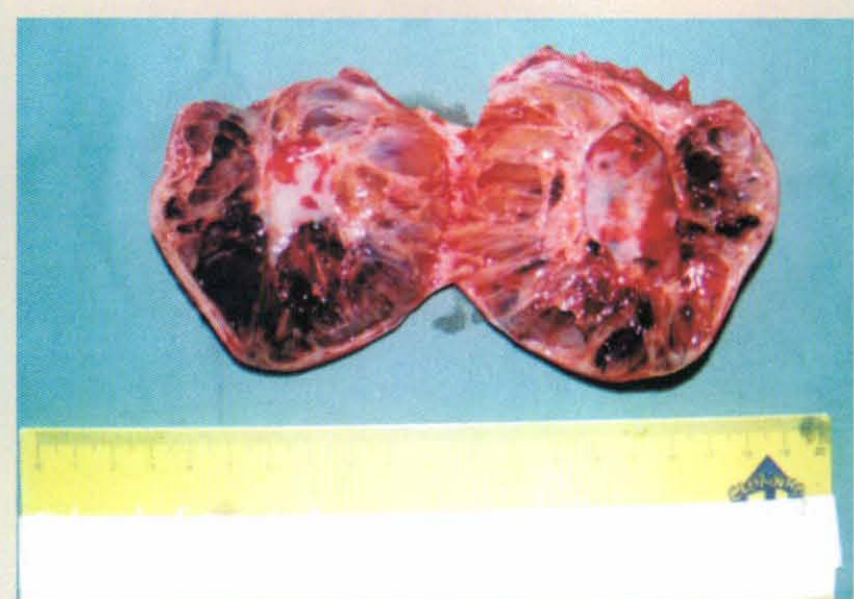

Figura 4. Peça cirúrgica ao corte, aspecto macroscópico - destacando-se $o$ aspecto de múltiplos cistos de diâmetros variáveis. 


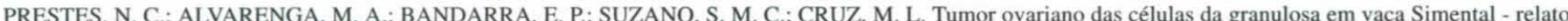

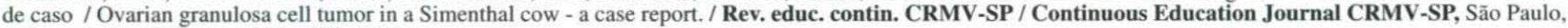
volume 4 , fascículo 1 , p. $028-032,2001$.

compatíveis com tumor das células da granulosa (Figura 2).

$\mathrm{O}$ animal foi submetido à ovariectomia unilateral pela fossa paralombar esquerda, sob anestesia local infiltrativa com xilocaína a $2 \%$. Após a remoção do tumor, ligadura do pedículo ovariano, sutura da parede do abdômen e da pele, instituiu-se antibioticoterapia à base de penicilina e curativo diário na ferida cirúrgica durante 10 dias, quando os pontos foram removidos. O ovário foi encaminhado ao Serviço de Patologia para exame macro e microscópico.

Macroscopicamente, o ovário esquerdo media $10 \mathrm{~cm}$, com superfície lisa e aspecto globoso, sendo ricamente vascularizado em sua superfície externa. Ao corte, observaram-se áreas císticas de diâmetros variáveis, contendo líquido amarelado ou sanguinolento (Figuras 3 e 4).

Para o exame microscópico, o fragmento ovariano foi processado e recebeu coloração pela hematoxilina e eosina. O exame histopatológico revelou presença de células da granulosa neoplásicas, divididas por cordões de células da teca. As células da granulosa apresentaram-se de forma poliédrica, com núcleos grandes, hipercromáticos, nucléolos evidentes, citoplasma escasso e eosinofílico. Figuras de mitose foram observadas com freqüência (Figuras 5 e 6$)$.

\section{Discussão e Conclusão}

Embora STICKLE et al. (1975), NYACK e JOHNSON (1983) e McENTEE (1990), relatem que o tumor das células da granulosa seja a neoplasia que mais acomete os ovários de bovinos, eqüinos e caninos, essa prevalência não foi observada na rotina de atendimento de grandes animais da Área de Reprodução Animal da FMVZ - UNESP - Botucatu. Esse tipo de tumor ovariano, em particular, foi diagnosticado com maior freqüência na espécie eqüina, na qual as éguas portadoras exibem manifestações caracterizadas pela ninfomania, comportamento masculinizado ou anestro prolongado compatíveis com os relatos de TURNER e MANNO (1983), PERINO e DIDIER (1985), DORAN et al. (1988), WILSON et al. (1989), HINRICH e HUNT (1991), McCUE et al. (1991) e HINRICH et al. (1992).

Neste caso, descrito em bovinos, o tumor era unilateral, sem evidências visuais de metástase, como as descritas por STICKLE et al. (1975) e McENTEE, em 1990. O diagnóstico da anomalia ovariana foi realizado pela pal-

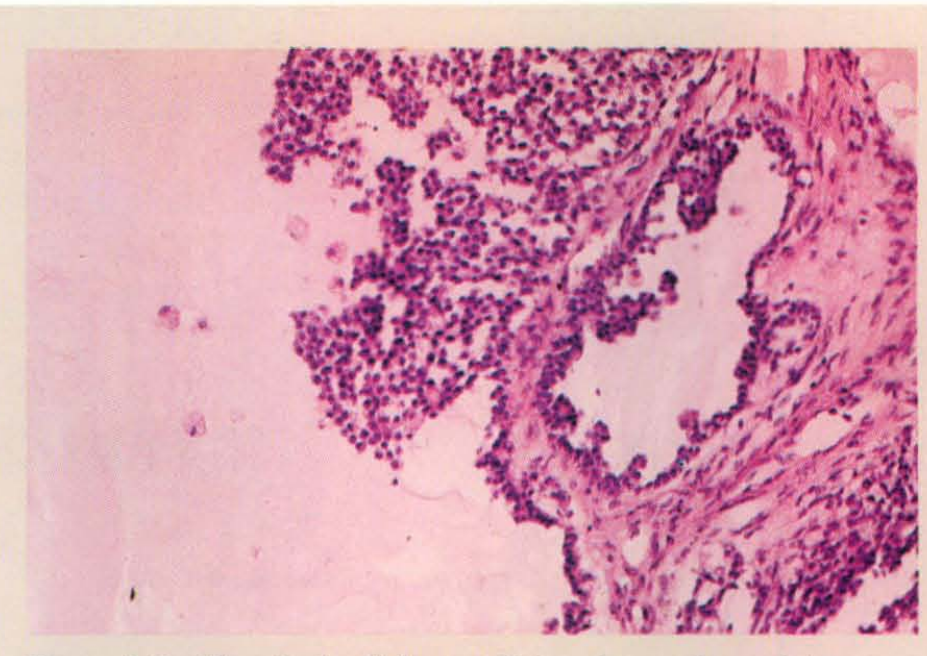

Figura 5. Proliferação de células neoplásicas da granulosa e da teca com formação de áreas císticas. Coloração HE, aumento 200x.

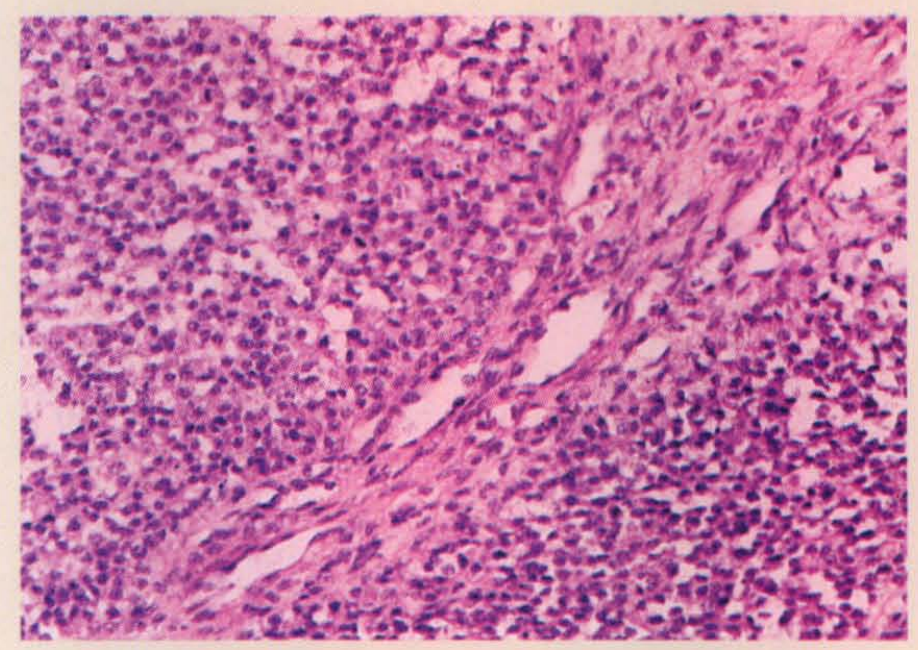

Figura 6. Células neoplásicas, observando-se freqüentes figuras aberrantes de mitose. Coloração HE, aumento 400x.

pação retal e ultra-sonografia, observando-se as mesmas características relatadas por WHITE e ALLEN (1985), HINRICH e HUNT (1990) e McCUE (1998).

A via operatória através da fossa paralombar permitiu fácil acesso ao ovário acometido e os achados macro e microscópicos foram idênticos aos de CORDES (1969), STICKLE et al. (1975), WHITE e ALLEN (1985), DORAN et al. (1988), HINRICH et al. (1989), WILSON et al. (1989), HINRICH et al. (1990), HINRICH et al. (1991) e McCUE (1998).

O protocolo anestésico utilizado mostrou-se eficiente e seguro e o exame ultra-sonográfico permitiu a mensuração do órgão, bem como a visualização das formações císticas, possibilitando estabelecer a suspeita do tipo de tumor, posteriomente confirmada pelo exame histopatológico 


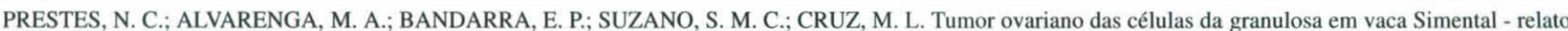

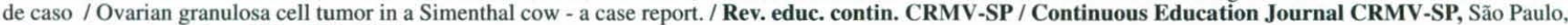
volume 4 , fascículo 1, p. $028-032,2001$.

\section{SUMMARY}

The objective of this study was to report a case of ovarian granulosa cell tumor in a 3-year old Simenthal cow. The neoplasia had $10 \mathrm{~cm}$ in its longest axis and its sections showed cysts filled with fluid and with different sizes. The histopathological evaluation confirmed the clinical diagnosis.

Key words: cow, ovary, granulosa cell tumor.

\section{REFERÊNCIAS}

1. CORDES, D. O. Equine granulosa tumours. Veterinary Record, n. 85 , p. $186-8,1969$.

2. DORAN, R.; ALLEN, D.; GORDON, B. Use of stapling instruments to aid in the removal of ovarian tumours in mares. Equine Veterinary Journal, v. 20, n. 1, p. 37-40, 1988.

3. HINRICH, K.; COCHRAN, S. L.; SCHELLING, S. H. Granulosatheca cell tumor associated with ovulation fossa and normal ovarian stroma in a mare. Journal of American Veterinary Medical Association, v. 200, n. 5, p. 696-8, 1992.

4. HINRICH, K.; FRASER, G. S.; DE GANNES, R. V. G. Serous cystadenoma in a normally cyclic mare with high plasma testosterone values. Journal of American Veterinary Medical Association, v. 194, n. 3, p. 381-2, 1989.

5. HINRICH, K.; HUNT, P. R. Ultrasound as an aid to diagnosis of granulosa cell tumour in the mare. Equine Veterinary Journal, v. 22 , n. 2 , p. $99-103,1990$.

6. HINRICH, K.; WATSON, E. D.; KENNEY, R. M. Granulosa cell tumor in a mare with a functional contralateral ovary. Journal of American Veterinary Medical Association, v. 197, n. 8, p. $1037-8,1990$.

7. McCOY, D. Diabetes mellitus associated with bilateral granulosa cell tumors in a mare. Journal of American Veterinary Medical Association, v. 188, n. 7, p. 733-5, 1986.

8. McCUE, P. M.; LE BLANC, M. M.; AKITA, G. Y. Granulosa cell tumors in two cycling mares. Equine Veterinary Science, v. 11, n. 5, p. 281-2, 1991.

9. McCUE, P. M. Review of ovarian abnormalities in the mare. In:

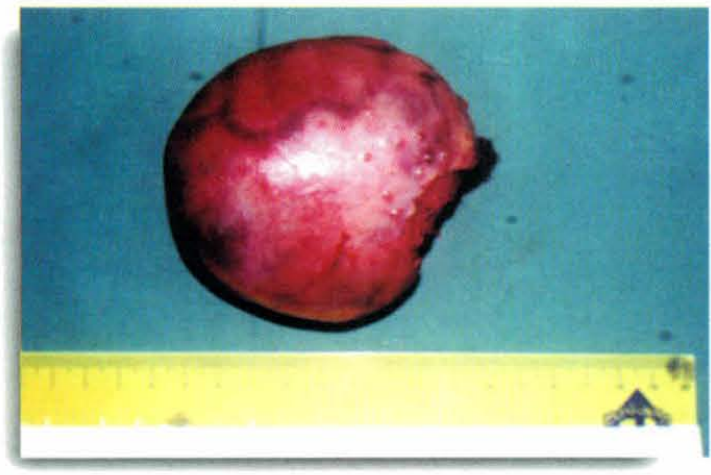

ANNUAL MEETING AMERICAN ASSOCIATION OF EQUINE PRACTITIONERS. 1998, Proceedings...1998. p. $125-33$.

10. McENTEE, K. Reproductive pathology of domestic mammals. San Diego: Academic Press, 1990. P.79-93.

11. NYACK, B.; JOHNSON, A. D. A mammoth granulosa cell tumor in a mare. Equine Practice, v. 17, p. 218-23, 1983 (February).

12. OBA, E.; SOZA, F. A. H., PAPA, F. O.; PRESTES, N. C. Tumor bilateral das células da granulosa em vaca - Relato de caso. In: CONGRESSO BRASILEIRO DE REPRODUÇÃO ANIMAL, 1987, Belo Horizonte: Anais...1987. P. 43.

13. PERINO, L. J.; DIDIER, P. J. Equine granulosa cell tumors. Equine Practice, v. 7, n. 4, p. 14-7, 1985.

14. STICKLE, R. L.; ERB, R. E.; FESSLER, J. F.; RUNNELS, L. J. Equine granulosa cell tumors. Journal of American Veterinary Medical Association, v. 167, n. 2, p. 148-51, 1975.

15. TURNER, T. A.; MANNO, M. Bilateral granulosa cell tumor in a mare. Journal of American Veterinary Medical Association, v. 182, n. 7 , p. $713-4,1983$.

16. WHITE, R. A. S.; ALLEN, W. R. Use of ultrasound echography for the differential diagnosis of a granulosa cell tumor in a mare. Equine Veterinary Journal, v. 17, n. 5, p. 401-2, 1985.

17. WILSON, D. A.; FOREMAN, J. H.; BOERO, M. J. Small-colon rupture attributable to granulosa cell tumor in a mare. Journal of American Veterinary Medical Association, v. 194, n. 5, p. 681-2, 1989.

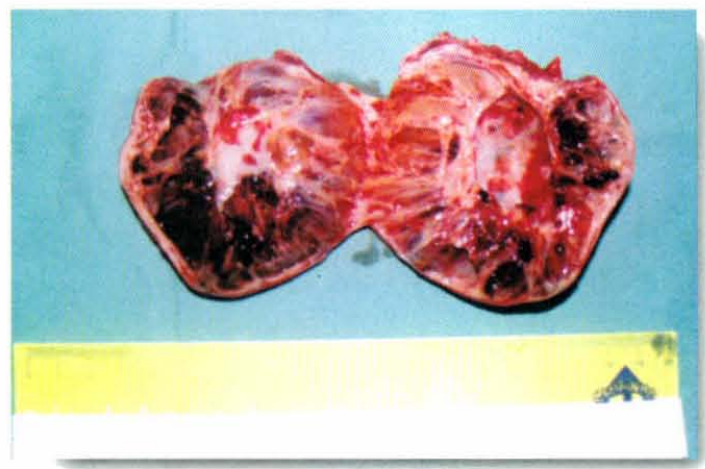

